\title{
A GOVERNANCE APPROACH FOR BIM MANAGEMENT ACROSS LIFECYCLE AND SUPPLY CHAINS USING MIXED-MODES OF INFORMATION DELIVERY
}

\author{
Yacine Rezgui $^{1}$, Thomas Beach ${ }^{2}$, Omer Rana ${ }^{3}$ \\ School of Engineering, Cardiff University, Cardiff, UK \\ E-mail: ${ }^{1}$ RezguiY@cf.ac.uk (corresponding author)
}

Received 26 Jan. 2012; accepted 16 Mar. 2012

\begin{abstract}
Built environment data is of varying nature embedding various forms of sensitivities with potential legal, contractual, intellectual property, and security implications. The paper presents a governance approach for managing multi-actor, multi-discipline, and total lifecycle data, informed by a wide industry consultation conducted in the UK between March and September 2011. The study identifies a number of barriers in engaging with Building Information Modelling (BIM) efforts with a view of facilitating collaboration around a common and integrated project specification. A governance model is proposed that addresses the identified adoption blockers underpinned by a "mixed approach", that factors in various modes of information delivery, ranging from paper-based documents to object-based information conveyed by IFC (Industry Foundation Classes). A demonstrator system is developed and used to validate our BIM governance concepts. Our governance model is discussed in the context of the recent UK government BIM industry consultation document supported by a research and development (R\&D) roadmap taking into account current industry structure and its various levels of stakeholders' maturity, capability and readiness.
\end{abstract}

Keywords: BIM, governance, supply chain, lifecycle, data storage.

Reference to this paper should be made as follows: Rezgui, Y.; Beach, T.; Rana, O. 2013. A governance approach for BIM management across lifecycle and supply chains using mixed-modes of information delivery, Journal of Civil Engineering and Management 19(2): 239-258.

\section{Introduction}

Construction and Civil Engineering are highly regulated, fragmented, data intensive project-based industries depending on a large number of very different professions and firms, with increasing data sharing and processing requirements (Rezgui, Zarli 2006; Anumba et al. 2008). The process of designing, repurposing, constructing and operating a building or facility involves not only the traditional disciplines (Architecture, Structure, Mechanical \& Electrical, etc.) but also many new professions in areas such as energy and environment (Rezgui, Miles 2011).

Construction is experiencing challenging operating environments with the emergence of new forms of procurement (including Private Finance Initiative, Public-Private Partnership and the design-buildoperate) and a new generation of clients demanding the delivery of value-added facilities within time and budgets (Barrett, Sexton 2006; Ulubeyli et al. 2010; Radziszewska-Zielina 2010).

Project failure has been common over the past decades, and amongst the notable common causes of failure is the lack of effective project team integration across the supply chain (Dainty et al. 2006; Zavadskas et al. 2010; HM Government 2011). In fact, there is an increasing alignment of interests between those who design and construct a facility and those who subsequently occupy and manage it. Inadequate information management is what contributes to delays and construction waste (Howard, Björk 2008). A lack of compatible information systems, de-facto standards and protocols, and the varying perspectives and requirements of clients and designers, have hampered widespread adoption of an adequate technology which has the capacity to ensure that all team members are working from the same data, and that: (a) the implications of alternative design proposals can be evaluated with comparative ease; (b) design artefacts are modelled in several dimensions thus eliminating coordination errors and subsequent expensive change; (c) design data can be fed directly to manufacturing environments eliminating unnecessary intermediaries; and (d) there is a proper basis for asset management subsequent to construction (HM Government 2011).

Moreover, data management across the project lifecycle and supply chain lacks an overall data management policy (Titus, Bröchner 2005). The UK 
government has realized the importance of built environment data and its strategic role in meeting some of its most pressing challenges, including the climate change and carbon reduction agendas, and has recently recognized the strategic role of BIM to address data, process and supply chain integration and to transform the habits and the structure of the industry (BIM Working Party Strategy Paper 2011). The UK Government will require fully collaborative BIM (with all project and asset information, documentation and data being electronic) as a minimum by 2016 (HM Government 2011).

$\mathrm{BIM}$ is the process of generating and managing data and information about a building during its entire life cycle from concept design to decommissioning (Howard, Björk 2008). Industry Foundation Classes (IFC - ISO/PAS 16739:2005 2005) are a commonly used form for BIM. They are open data model specifications for defining building components' geometry and other physical properties in a way that enable CAD users to transfer design data between different software applications (Howard, Björk 2008; Smith, Tardif 2009). They are intended to provide an authoritative semantic definition of building elements, their properties and inter-relationships. Data associated with IFC can include: textual data, images (such as building schematics); structured documents, numerical models and designer/project manager annotations. The IFC specification is developed and maintained by BuildingSmart and has been included in several ISO standards. The IFC with its standard set of rules for data storage, data exchange and protocols provides an ideal framework to manage data related to a building throughout its lifecycle.

The current status of adoption of the IFCs is relatively low (Serror et al. 2008) and there are a number of barriers that BIM technology proponents need to address before industry wide acceptance (Ashcraft 2008). This paper is based on a large consultation to explore the nature and causes of these barriers with a view of developing a governance model that factors in the multi-discipline, multi-actor and lifecycle complexity of construction projects. Following this introduction, the paper discusses related work from a BIM adoption, data governance, standards, and data storage and access perspectives. The methodology that underpins the research and the results from our wide industry consultation are then presented. This is followed by the description of our BIM governance model informed by the recommendations from our industry consultation. The paper then discusses the validation of the governance model through the CloudBIM demonstrator and proposes a roadmap for wide BIM adoption and diffusion. Finally, the paper provides concluding remarks and discusses directions for future research.

\section{Related work}

This section draws on existing literature and reports on related BIM adoption, governance, information standards and implementation research. We define governance in this paper as the process of establishing a project information management policy across lifecycle and supply chains underpinned by a building information model taking into account stakeholders' rights and responsibilities over project data and information. A governance model is a conceptualization and specification of this project information management policy in a way that can be implemented and used in a computerized environment.

\subsection{BIM adoption in industry}

The construction industry is often portrayed as involving a culture of "adversarial relationships", "risk avoidance", exacerbated by a "linear workflow" (Succar 2009). According to an interesting and recent study (McGraw Hill 2010) architects have the highest level of BIM adoption and proficiency in Europe. Nearly half of architects $(46 \%)$ have adopted BIM, with $42 \%$ of architects creating BIM models and 19\% also analyzing them. Today, $48 \%$ of architects who use BIM consider themselves advanced or expert. Conversely, about 4 in 10 engineers (37\%) use BIM. They lag behind architects but lead contractors in adoption. Interestingly, this adoption level among engineers in Western Europe is almost as high as among engineers in North America (42\%) who were shown in the 2009 North American study to be somewhat resistant to fully embracing BIM technology. Contractors have the lowest level of BIM adoption and proficiency, with only $23 \%$ saying that they are using BIM and only one quarter $(26 \%)$ indicating that they consider themselves expert or advanced. Contractor adoption is also the most recent, $68 \%$ having begun using BIM in the past 3 years.

Rezgui and Miles (2011) used a combined Technology Acceptance Model and Diffusion of Innovation theory to explore factors affecting BIM adoption. Issues have been identified in terms of perceived usefulness and ease of use of BIM complemented with factors related to compatibility, observability, triability, and competitive advantage of BIM technology. In the majority of BIM adoption initiatives, technical problems (including compatibility and reliability), team fragmentation, resistance to change, lack of training, and business process related issues are often cited as barriers to BIM adoption (Howard, Björk 2008). Moreover, there is an acknowledged uncertainty about the legal, contractual and overall organisational implications of BIM (Ashcraft 2008; Chao-Duivis 2009). There is a consensus that socio-organisational and technical changes should accompany BIM deployment efforts (Rezgui, Miles 2011). However, there is no consensus as to who owns the model (BIM) and who is 
responsible for financing and maintaining it over the facility lifecycle (Eastman et al. 2011).

\subsection{BIM governance}

Overcoming the above mentioned BIM adoption shortcomings requires development of protocols, setting up responsibilities among disciplines, sharing through a common model (which can be stored centrally or outsourced); and overall, a better communication among disciplines (Eastman et al. 2011). It also requires awareness, intensive trainings and defining formal responsibility among stakeholders, across disciplines and the lifecycle (Smith et al. 2005; Rezgui et al. 1998).

Singh et al. (2011) identify a number of technical requirements for a suitable collaborative BIM, including: centralized model repository linked to other federated data repositories; different spaces for public and private models; object identification by Globally Unique Identifier; specifications based on Information Delivery Manuals (IDM); secure access to the model; hierarchical model structure based on user requirements; security checks for uploaded/downloaded and transferred models; customizable user interface; realtime viewing and printing through the web; submodels, and objects with different levels of detail and ease in checking properties of the objects.

A number of commercial solutions addressing part of the above limitations have been developed. Commercial BIM servers are today available, including the Onuma system (www.onuma.com), Revit Server (www.autodesk.com), ProjectWise and AssetWise (www.bentley.com), Graphisoft BIM Server (www.graphisoft.com) and EDMmodelServer (www. jotne.com). These environments tend to use proprietary governance data structures. They tend to adopt either central (accessible to all team members over the WAN) or local (accessible to team members over the LAN) servers for data storage and management.

Distributed data storage technologies, including cloud, are becoming increasingly prominent. NIST (National Institutes of Standards and Technology) define Cloud Computing as a model for enabling ubiquitous, convenient, on-demand network access to a shared pool of configurable computing resources. More specifically Cloud Computing can generally be thought of providing Infrastructure (Processing Power and Storage), Software or the computing platform itself to users (Kim, Parashar 2009).

One of the limitations of commercial cloud storage technology is that the process dimension is not factored into the storage and data access strategy. Current cloud-based solutions tend to be proprietary and data access follows a company policy and don't address the process dimension of a given project across its supply chains and lifecycle (Rana et al. 2011).

\subsection{Related standards and developments}

A number of semantic resources and information management standards have been developed for the construction domain. These include COBie (Construction Operations Building Information Exchange), agcXML, and BS1192:2007 (2008). COBie is developed as a standard data specification for structured information exchange (East 2010). The COBie approach and concept is to input data and information during the processes of design, construction, and commissioning, which will essentially support the operations, maintenance, and the management of the facilities by the owner and/or facilities manager. It provides overall traceability and visibility of design, construction and handover information and decisions. agcXML, a buildingSMART project as part of the aecXML Domain framework, aims at producing a set of eXtensible Markup Language (XML) schemas of structured format for the exchange of information during the design and construction process through any number of documents including request for information and change orders amongst others (BuildingSmart 2010). BS1192:2007 (2008) is a standard for collaborative production of project information which provides a naming convention constructed using specific metadata fields. These standards complement the IFC development efforts and are a good contribution towards addressing some of the BIM shortcomings.

\section{Methodology}

A methodological challenge for the research is to avoid a narrow scoping of the research question(s) so that to provide a stimulus for meaningful engagement by the industry participants. Evidence from behavioural decision research indicates that people do not come to complex technological issues with comprehensive views but can be supported in the construction of their preferences through systematic elicitation and deliberative procedures. Hence, the research utilises a qualitative approach involving two deliberative workshops (which have attracted 75 industry representatives) and 4 focus group meetings (with a total of 20 participants) incorporating qualitative methods of inquiry over a duration of 5 months (February 2011-June 2011). The research is located within theoretical traditions that take socio-technical systems as the focal unit of analysis. This perspective provides a robust foundation for analysing linked processes of social and technological practices related to the process of designing, constructing and operating a building or civil facility.

The overall aim of the research is to explore the potential for a governance model to enhance stakeholders' experience with adopting BIM across the lifecycle of a building or civil infrastructure. More 
specifically, the research addresses the following three research questions:

- RQ1: What are construction stakeholders' socioorganisational and technical barriers to BIM adoption?

- RQ2: Would these barriers be addressed through a governance approach that factors in the multidisciplinary, multi-actor, and lifecycle dimensions of projects?

- RQ3: What implementation environment is best suited to address data sharing and computing needs of construction stakeholders?

The above research questions involved an industry consultation through a deliberative workshop organized by the Modern Built Environment Knowledge Transfer Network (MBEKTN) coordinated by BRE (Building Research Establishment). 75 participants registered to the event. This involved representatives from a variety of organisations across the architectural design (33\%), engineering (31\%), and ICT $(26 \%)$ disciplines. The second deliberative workshop discussed the proposed governance model development work informed by outcomes from the first workshop. This involved 16 industry participants that covered the project management, design, and engineering disciplines. The results from these 2 workshops fed forward to a series of 4 focus group meetings to validate the governance model and its implementation. These were organised with 4 companies, namely Bentley Systems (a leading CAD editor), Scott Wilson (a leading construction company with strong involvement in BuildingSMART and UK government BIM related initiatives), ARUP (a leading engineering company), and LeeWakemans (a project management company). It is worth noting that the success of our consultation can be explained by its timing in relation to the publication of the BIM Working Party Strategy paper (2011). SME participants from the construction industry perceive the government BIM drive as a threat and an opportunity: a threat, if they don't adapt in time to the government requirement to deliver BIM compliant project information; and an opportunity, if they exploit BIM effectively to create a competitive advantage and establish a market leadership.

\section{Results from the consultation}

The first workshop covered the three research questions (RQ1, RQ2, and RQ3) and involved three parallel sessions where business, legal and technical barriers were discussed, as summarized in Table 1. The first part of the workshop focussed on RQ1, and then after convening, RQ2 (governance model) and RQ3 (BIM implementation environment) were discussed using a deliberative workshop format chaired by a professional facilitator.
One of the interesting issues that were debated relates to the scope and format of BIM. It was evident that BIM meant different things across the workshop participants with some relatively shared views across disciplines. One of the designers from a London-based architectural practice commented: "BIM is in my view a more comprehensive and detailed computer-based description of drawings compared to traditional CAD as it requires designing in $3 D$ and defining all building elements performance and characteristics". Another participant from a leading contracting organisation argued that: "the main application of BIM is to provide a document store that facilitates access to key design and engineering project documentation during the construction stage". This triggered a comment from a participant representing a large client organisation who argued that: "BIM is a tool for clients to enforce requirements and project performance satisfaction while at the same time delivering a virtual project alongside the handed over facility". This was corroborated by a representative from a Facility Management organisation that noted: "I fully agree in fact, this virtual building will enable us to perform value added facility management". Workshop participants then reached a consensus around one participant from an ICT company who commented: "The main feature of BIM is that it requires collaborative design development from a common building model as opposed to a variety of drawings facilitated by a model server or large distributed database which embeds geometry as well as various building properties. This intelligent model will help designers easily detect conflicts and clashes due to multi-disciplinary collaborative evolution of the design".

There was then an interesting debate on whether BIM should be limited to structured IFC like objects or include traditional legally binding documents. There was an overall agreement that BIM would require a cultural change across the industry as reported by a participant from Bentley (one of our project partners): "There seems to be a push towards using a database approach towards BIM where management is applied at building element level. However, the industry is not ready. While our tools (Bentley) are all IFC compliant, we are still experiencing a slow move towards exploiting the strength of BIM servers. Clients, designers and contractors still demand and rely on frozen technical drawings which carry a contractual and legal dimension". He then went on arguing the need for a "mixed approach" which acknowledges the co-existence of paper-based or electronic frozen documents and a live/evolving IFC model. BIM would involve both types of project data representation, i.e. paper-based and model-based.

Another issue, which involved interesting discussions, relates to the return on investment of BIM. There was an overall consensus that BIM adoption may involve initial losses as many practitioners will 
Table 1. Key results from our consultation

Category of

Barriers

Key Results from the Consultation

Organisational

- There is a strong culture of reliance on paper-based legally binding documents (including technical drawings).

- The separation between design and construction activities in some procurement paths hampers the integration of building life-cycle information in BIM.

- Dominance of SMEs in various parts of the lifecycle, in particular during the construction stage with limited process and technical maturity and capability.

- Limited investment in ICT due to tight financial margins on projects.

- BIM should involve rethinking and mapping project stakeholders' authorities, responsibilities and financial arrangements linked to virtual buildings as opposed to frozen paper-based documents.

- Traditional procurement paths that hinder collaborative working across the supply chain from concept design.

- Financial arrangements that prevent early involvement of stakeholders in the design process, e.g. contractors assisting in product and material selection.

- Who covers the additional costs involved with adopting a BIM approach? Is this covered by the client or shared across stakeholders?

Legal - There is no clarity as to who owns and is responsible for BIM.

- IFC data or IFC servers carry no legal or contractual obligations. What ultimately matter are the contractual drawings and specification documents.

- BIM does not involve any liability in case of wrong or incomplete information when it comes to resolving disputes.

- Current procurement paths are not adapted to the nature of BIM and important issues related to intellectual property rights and fait-practice exist.

- BIM does not embed stakeholders' roles, responsibilities and authorities reflected in rigorous access control on data. This opens avenues for accidental and unwanted changes.

Technical - Lack of compatibility between various IFC products. There is loss of semantics during IFC import and export between different IFC-based packages.

- Fragmentation of BIM data across design and engineering teams and then the contractor and FM companies.

- Information is not sustained across the lifecycle and is in continuous danger of being lost due to company mergers or bankruptcy.

- Access control to data is addressed by commercial and proprietary solutions that are not compatible and do not embed the project procurement path and process dimension.

- BIM data is not secure even when stored on BIM servers, as these are managed and controlled by a single company or at best outsourced to a data centre.

- The network and communication overheads in using externally sourced virtualized storage.

- Privacy constraints associated with utilizing such storage for business sensitive data, as viewed by industry end users.

- Support for data integrity, user authentication, data security, and access control.

have to proceed by "learning-by-doing" as corroborated by Sebastian (2010). However, companies should be able to reap the benefits of BIM once business processes are re-engineered and adapted and also on long-term contractual arrangements which include operation management. Hence, education and training are important enablers and companies should invest in the development of their staff. The same participant from Bentley argued that: "the challenge is to live with incomplete or uncertain information. A true BIM approach involves stakeholders across the design and construction stages, including contractors collaborating towards the selection of the best design options such as sustainable materials and products. However, current and traditional procurement paths can act as barriers. This has implication on financial arrangement across the supply chain".
Following from the discussion on the definition, scope and format of BIM, the legal dimension of BIM was raised. The discussions converged to identify two main streams of legal barriers as reported by a participant from the legal and contract department of a large contracting company: "The legal aspects of BIM boils down to two issues on the one hand, the governing dimension of information and ways in which this is shared and communicated on projects across the supply chain and the lifecycle, and on the other, the project-specific procurement and related contractual arrangements". There was an agreement that the former issue (information governance) is unregulated and carried out in an ad-hoc way while the latter issue (procurement path) is contractually sound but involves important gaps as reported elsewhere (Chao-Duivis 2009). This was best described by a 
participant from a contracting company who commented: "In a traditional procurement path we always face problems in importing the design team "BIM" into our own system. There is always a loss of data during the file import which results in considerable time spent to complete the model'. This was corroborated by an architect who pointed out that: "The transferred BIM embeds some form of know-how and intellectual property which is not covered by current procurement methods". The contractor then replied: "Correct, however, there is equally no liability as to the correctness of the information conveyed through BIM which in some instances differs from the same information provided through contractual documents such as detailed drawings". This was corroborated by the participant from the legal and contract department of a contracting company who concluded: "There should be a close in the contract that spells out the legal implications in terms of responsibilities and liabilities when wrong or incomplete information is found. Our profession has to catch up with the fast development of technology and $B I M$ '.

These concerns were confirmed in the second part of the workshop, which focussed on discussing indepth issues related to Trust, Security, Privacy, Interoperability, Ownership and Rights of BIM data. There was a general consensus that a neutral (non-proprietary) BIM governance model should be developed which would bind all stakeholders across disciplines and lifecycle around a shared BIM experience.

The authors then explored the third research question by inviting workshop participants to reflect on their experience of storing and accessing BIM data and related project documentation. This revealed mixed and ad-hoc ways of dealing with project data, including BIM. Variations involved a number of factors, including project size, client's standing (small, medium or large client organisation), procurement path, design and contractor BIM awareness and ICT maturity. This was best summarized by the participant from Bentley who commented: "Our experience with dealing with data storage using our commercial system (ProjectWise) is that our customers depending on their role in the project would either install ProjectWise on their company server for their employees' data and document sharing needs using their company access policy or open it up for all project participants again using their own policy and financial charging model". This triggered a number of criticisms from the participants arguing that not everyone was familiar with ProjectWise and that they had already invested in developing or deploying a different project management system. Also, issues related to process and procurement path compliance of these systems were raised. This reinforced (a) the need for an open and non-proprietary model as is the case of the IFCs, and (b) the need for a more robust and sustainable storage solution.

\section{A governance model for a mixed-mode delivery of building data and information}

A building information model at the very simplest level can be viewed as the complete collection of information about a building, offering a phaseless workflow (Succar 2009). This BIM data is accessed and manipulated by utilising certain "tools of enquiry", such as "lenses" and "filters"; lenses highlight certain objects that meet a particular criteria (e.g. columns on floor level 2) whilst filters remove objects that do not meet the criteria.

However, results from the consultation suggest that this idealised view of BIM data does not match traditional and current industry requirements. To this end, this section describes a governance model to enable multi-actor, multi-discipline, and lifecycle management of BIM artefacts (i.e. project documents and model-based data). It is interesting to note work by Kubicki et al. (2006) aimed at developing a relational cooperation model with a view of conceptualizing relationships and interactions between actors on a project, their activities, the artefacts they produce, and the tools they use. While the latter is meant to facilitate coordination of construction activities, our model will enable the capturing and modelling of the often complex data access requirements within the collaborative working environment that is prevalent within the construction industry, facilitating the adoption of BIM by industry and helping to alleviate the security, responsibility, ownership, and IPR concerns held by many in the industry.

The first step in the creation of our governance model is the identification of key characteristics of building information models, their users, and the process dimension. Five key areas emerge from our analysis of previous research and information gathered from our consultation with industrial partners:

- The conceptualisation of building artefacts (including data) within a BIM model;

- Relationships between these building artefacts within BIM;

- The life-cycle of a building;

- Users of multiple disciplines acting on BIM at different stages of the lifecycle;

- Controlling the access rights to BIM artefacts.

These areas have been validated within our focus group discussions and involved incremental refinement. This section will describe each of these key areas in detail, highlighting the underpinning model and its development into a concrete implementable governance model. Additionally, we will also describe other 
functionality that has been highlighted as important by our research.

\subsection{Conceptualisation of data within a BIM model}

A building model can be made up of many different types of information, possibly stored in different forms and formats, from different contributors, many of whom belonging to different disciplines. One of the key concerns noted during our consultation is that industry is reliant on "document" based view of data. This stems from requirements for having legally and contractually binding documents, which convey a frozen state of the building project at a given point in time.

To address this concern our governance model provides the conceptualisation that BIM in its simplified and pragmatic form is a set of related paper-based and/or electronic (including model-based) resources, as illustrated in Fig. 1. It is important to emphasize that in the reminder of the paper we decouple the concept and definition of BIM as widely accepted by the academic community from the possible modes of BIM delivery (as illustrated in Fig. 1), taking into account current stakeholders' capabilities and information delivery on projects. Our approach is motivated by the key recommendation from our consultation that we need to manage the transition from current mixed-modes of BIM-data delivery to a fully model-based IFC approach. Hence, in the context of this paper BIM is defined as: $A$ set of BIM data available in the form of "BIM artefacts" as illustrated in Fig. 1.

While currently BIM consists of a variety of paper-based, structured, unstructured, object-based (stored in a BIM server) artefacts, it will eventually be managed as one, open, standardised logical model, an example of which could be the IFCs (ISO/PAS 16739:2005 2005). The current situation means that until such a level of maturity is reached, we need to adopt a "mixed-approach" handling different forms of information delivery as illustrated in Fig. 1.

\subsection{Relationships between BIM artefacts}

Within our governance model we model a BIM as a collection of BIM artefacts. However, rarely within such a model can any two BIM Artefacts be treated as completely separate entities and many will have relationships with others within the project model space. Incremental refinements within our focus groups consultation led to the classification of these relationships into five types: versioning, optioning, composition, derivation and concurrency. Each of which have different implications as to how data within the BIM as a whole is affected when a new BIM artefact is added. We identify six scenarios as discussed below.

Scenario 1 - No relationship. This scenario relates to the simple addition of a BIM artefact to the project BIM space.

Scenario 2 - Versioning. This scenario describes the creation of a new BIM artefact based on an existing one with changes made resulting from updating and/or removal of existing data, or/and addition of new data. An example of this relationship is shown in Fig. 2.

Scenario 3 - Optioning. This scenario describes the creation of one or several BIM artefact(s) option(s) from an existing BIM artefact. This is illustrated in Fig. 2.

Scenario 4 - Derivation. A new BIM artefact is created based on an existing BIM artefact. This mainly happens when a document used in one discipline, for instance Architecture, is used to derive a BIM artefact from another discipline, e.g. Structure. This involves filtering unneeded data and adding the discipline specific new data.

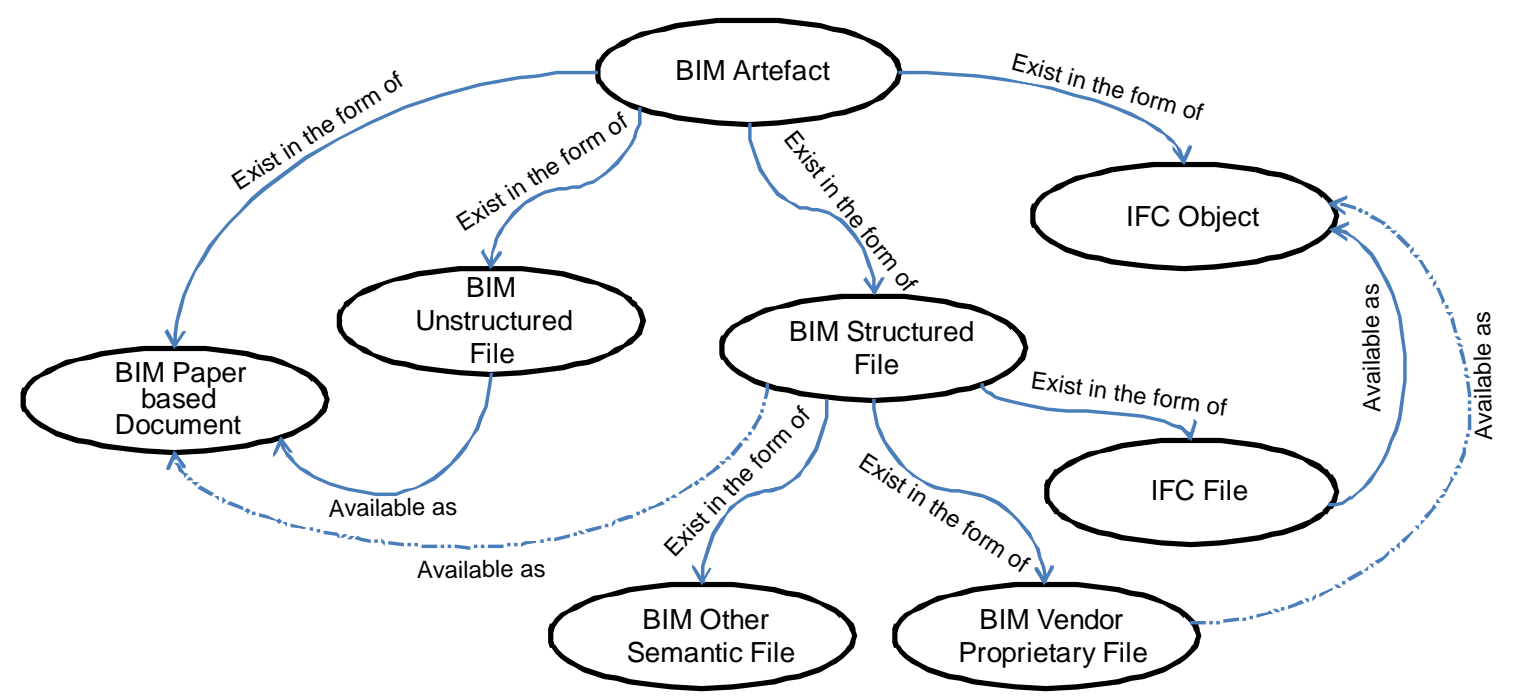

Fig. 1. BIM artefacts 


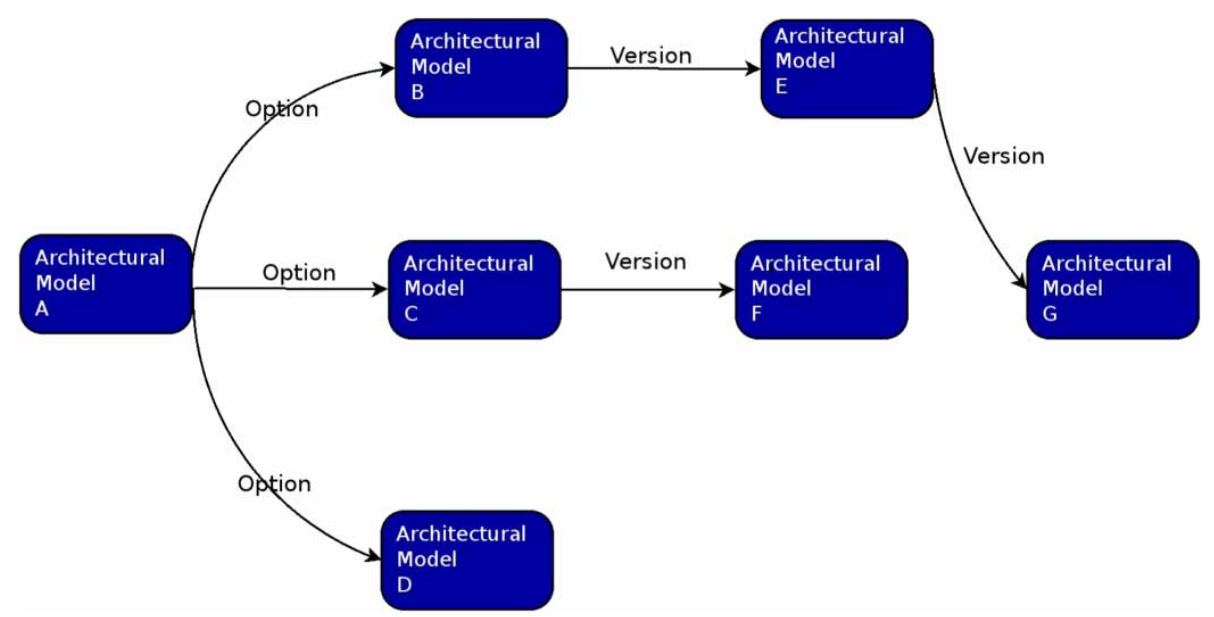

Fig. 2. Optioning and versioning relationship

Scenario 5 - Composition. New data is added to the BIM model forming part of an existing BIM artefact. An example of this relationship is shown in Fig. 3. This composition model allows for the construction of BIM artefacts, made up of other BIM artefacts, with each possibly possessing different access rights. This provides great flexibility for situations where an individual user may only have access to modify certain parts of a larger BIM artefact.

Scenario 6 - Concurrency. The concurrency relationship is a two way relationship used to model situations where two BIM artefacts are developed in parallel and illustrates a dependency between the two. This means that whenever a BIM artefact on one side of the relationship is viewed, the contents of the other BIM artefacts are also displayed.

These relationships allow us to easily model five of the most common occurrences within a construction project:

- When a user, such as an engineer designing a building structure, or internal building services, begins work on their design, they will require some of the information already present in the architect's design. This is the derived from relationship and it allows a user to create a document that uses some or all of the information from another document;

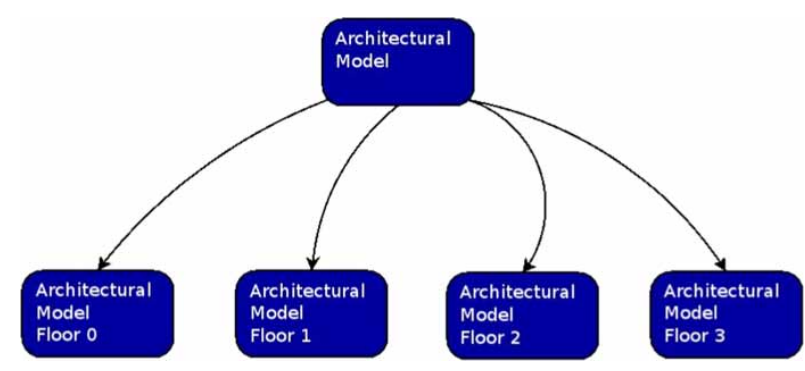

Fig. 3. Composition relationship
- The version of relationship allows us to model the scenario when changes are made to an existing document leading to the creation of a new version;

- The option of relationship allows the modelling of complex design situations that can occur within a construction project, where several parallel options may be developed for experimentation by an architect before a final option is chosen for full development;

- The composition relationship allows the representation of a BIM artefact as a collection of several BIM artefacts, i.e. when each floor of a structure is modelled separately they can all be linked together as part of the BIM artefact representing the complete structure;

- The final relationship type considered is the concurrency relationship. This allows for situations when two BIM artefacts are worked on concurrently and changes in one must be reflected in the other. An example of this occurrence could involve the structural design of a building where an architect and structural engineer must work closely together to resolve a number of design situations.

The relationships defined here apply equally whether a given BIM artefact is stand alone, or part of a unified BIM data model. However, the latter case allows far greater power when reasoning about BIM artefacts, due to the structured (model-based) and standardised nature of the underlying data. Examples of this include:

- The ability to automatically filter data within a BIM artefact when making a derivation for use by another discipline;

- The ability to automatically determine and manage changes between versions of the same BIM artefact; 
- To handle versioning on the object level such as described in Koch and Firmenich (2011);

- To automatically manage the separation of objects between BIM artefacts within the concurrent relationship.

\subsection{The Process of building information modelling}

Despite the fact that a BIM should offer a phaseless workflow (Succar 2009), there is still a definite industry requirement for the use of methodologies such as the RIBA project stages (RIBA 2007) or any similar process to manage construction projects and this must be taken into account when developing a governance model. This means that in order to meet industry needs our governance model must not only facilitate controlled access to building artefacts (i.e., data and project documents), but it must also provide an awareness and implementation of the process behind that data.

This means that a BIM must allow the building to be modelled across its entire life-cycle, from concept design through construction, operation and finally to decommissioning. This entire process would prove impossible to manage collectively, so our governance model divides this into stages. However, within the construction industry there are many "standard" approaches to managing a construction project. The most widely known of these is in the UK the RIBA plan of work, but many others exist. For this reason any model defined must be flexible enough to model all of these processes. It is for this reason we selected a powerful, but generic approach, shown in Fig. 4.

In our approach we define that each building information model is developed across a series of stages, at the end of which there is a gate. A "Gate" defines a project milestone and check-point at the end of a "Stage" where a number of BIM related requirements have to be considered prior to progression to the follow-on stage. Hence, each "Gate" within the system defines a set of either mandatory or optional BIM requirements such as:

- Presence of data within the BIM, e.g. detailed description of components (in terms of materials

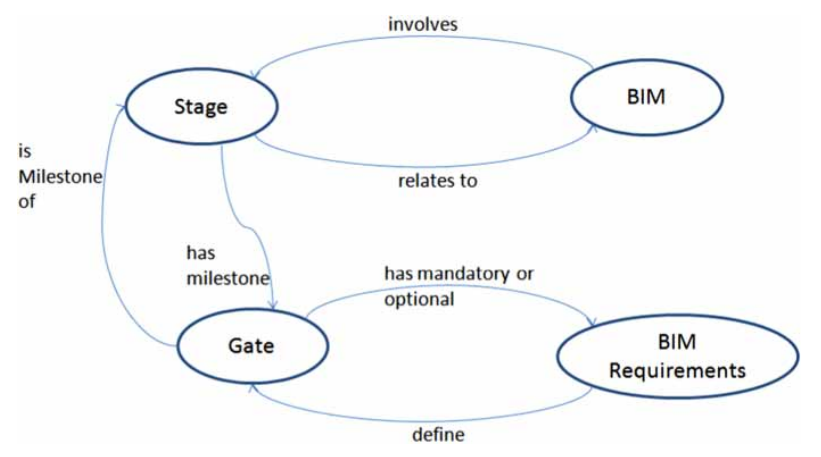

Fig. 4. Structure of a BIM and their performance) may not need to be fully detailed in the "outline design" stage; however, this should be mandatory in the "detailed design" stage. In this instance, the gate requirement would define the optional and mandatory levels of description of components;

- Level of accuracy of data, e.g.: (a) Structural data during the "outline proposal" stage should provide an initial sizing of the structure; however, the structural sizing in the "detailed stage" should be accurate, i.e. result from detailed/ validated calculations; (b) "outline proposal" building energy figures may be rough estimates as opposed to the "detailed stage" where these should be established and simulated using detailed calculations and proven algorithms.

This functionality will enable the use of the governance model as support for project managers, enabling the creation of reports that can be used to facilitate design making and ensuring the BIM compliance with set standards, whether imposed by legislation, the client, or internally. In addition, this division into stages allows the tracking of the BIM model throughout the project process. In essence each stage within the model can be viewed, once it has completed, as a snapshot or frozen view of the BIM as it was at that time.

\subsection{Multi-user collaboration}

Fig. 5 shows the overall architecture of BIM artefacts within our BIM governance model. There is one additional concept that has been introduced here to facilitate collaboration, which is document suitability. Based on British Standard 1192:2007, a document's suitability allows the modelling of a document through its life-cycle. Illustrating the different ways in which a document can be used. Currently we define five document/BIM artefact suitability types:

- Private: BIM artefact only for use of owner;

- Team: BIM artefact only for use at a team level;

- Finalised: BIM artefact is finalised for use by other teams;

- Client: BIM artefact is ready for release to client;

- Archived: BIM artefact has reached end of its lifecycle and no further alterations will be made.

Fig. 5 also introduces the concept of transactions. Whenever a relationship between BIM artefacts is created, a transaction, triggered by a decision made by a user, occurs (Rezgui et al. 1998; Cooper et al. 2005). The transaction entity is generated automatically, whereas the decision entity enables the user to make the reasons for the action they took explicit. Fig. 5 also shows all the metadata that is stored regarding BIM artefacts. When designing this metadata we selected as a base-line the Dublin Core 


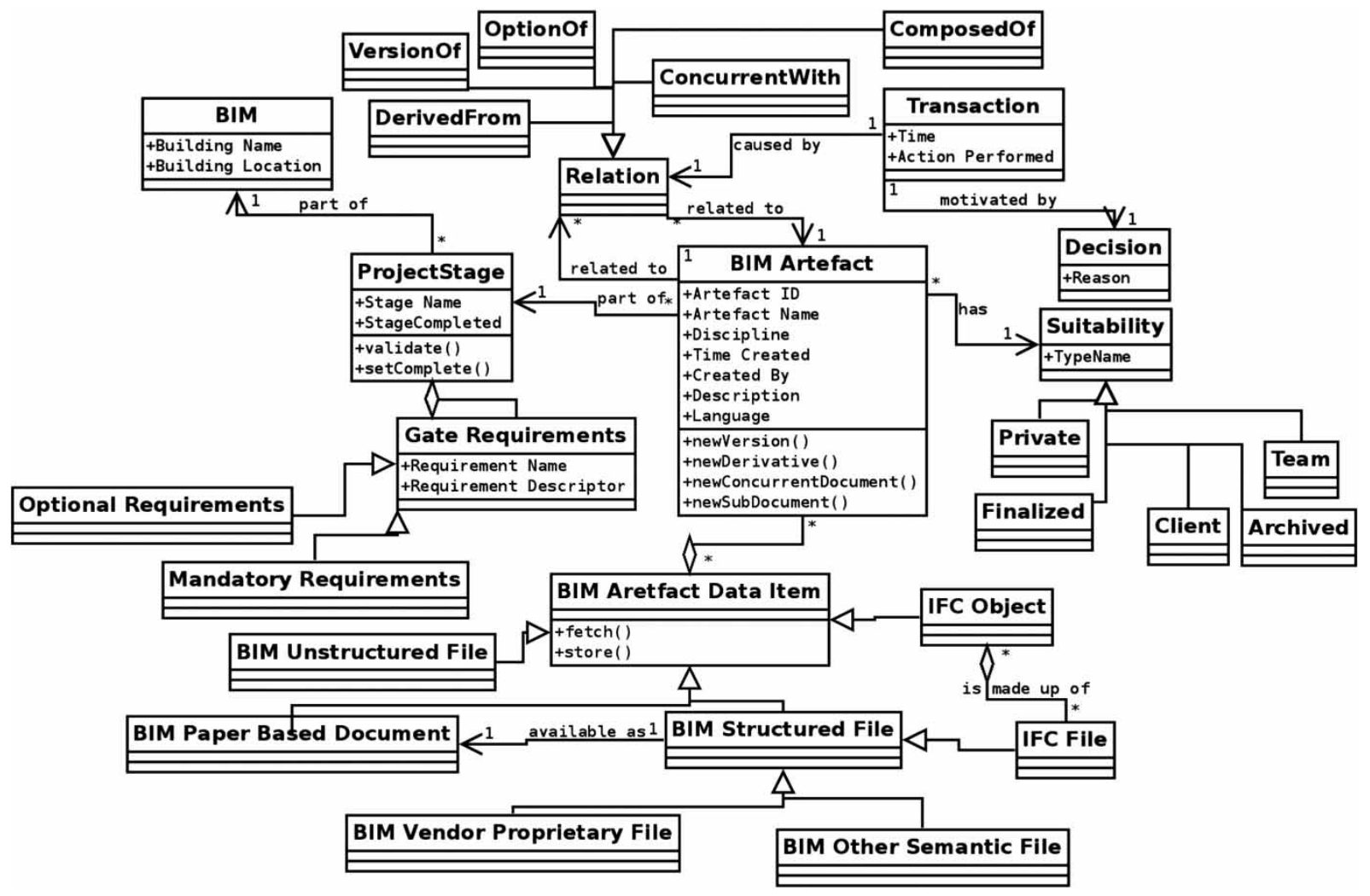

Fig. 5. BIM artefacts conceptualization

metadata standard ISO 15836, ensuring that all elements defined in this standard are either provided explicitly within the BIM artefact object, or implicitly by its relation to data stored in other related objects within the governance model.

\subsection{Access rights, users, disciplines and roles}

Previously we have described how a BIM models a building through its entire life-cycle as a collection of related BIM artefacts, each possessing their own life-cycle. However, in order to properly enforce control of these BIM artefacts, finer grained control is needed than what is provided by the concept of document suitability. Hence, rigorous access controls are needed.

In order to achieve this, the concepts of users, disciplines, rights and roles are introduced to the governance and their interactions are shown in Fig. 6:

- Users - A user is a single actor within the system;

- Disciplines - An industry recognised specialisation working on a specific aspect of a project;

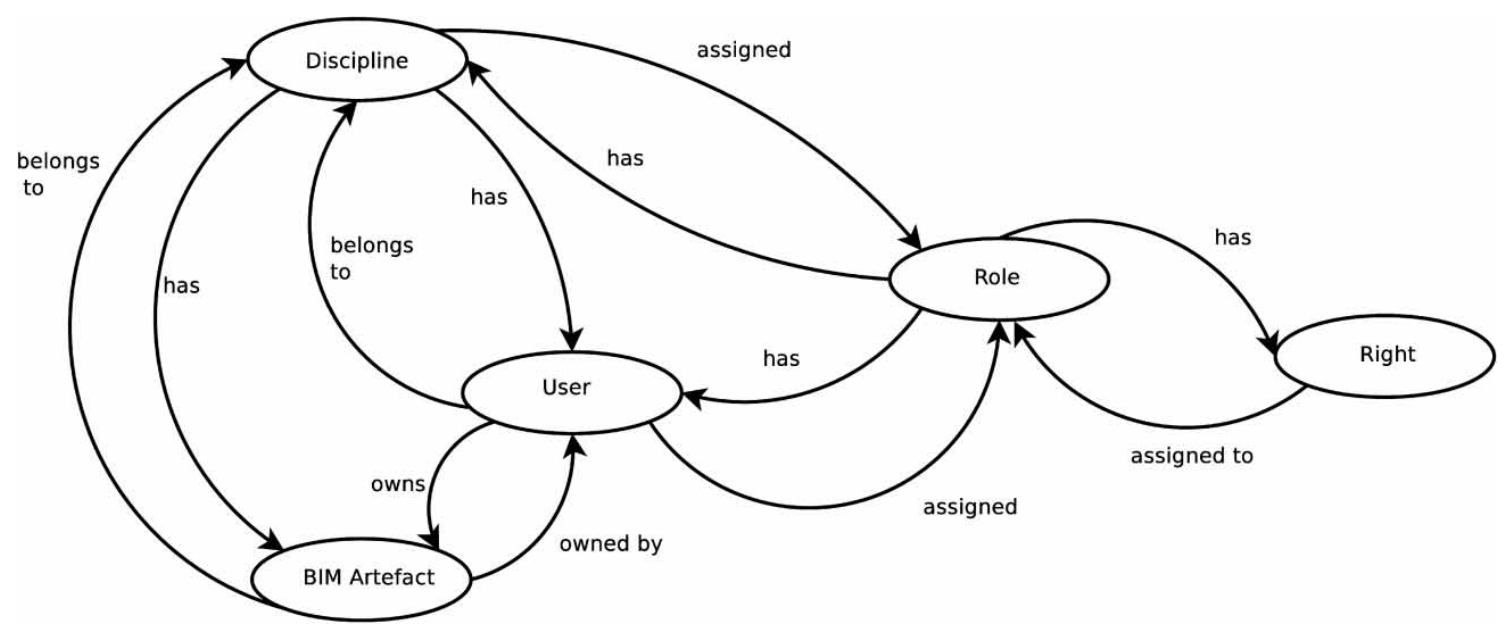

Fig. 6. Users, disciplines and roles 


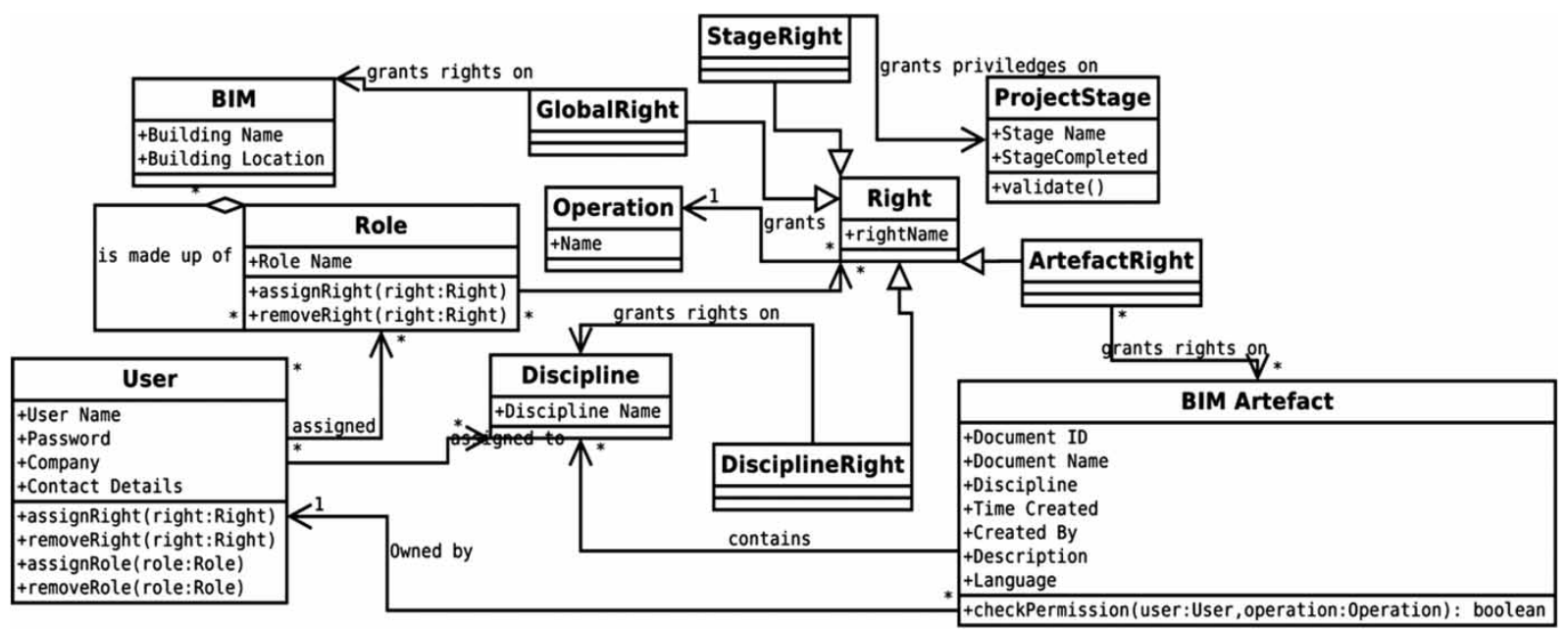

Fig. 7. Implementation of users, disciplines and roles

- Rights - The conceptualisation of a permission to perform an operation on a BIM artefact;

- Roles - A grouping of rights that can be applied to users or entire disciplines.

A detailed diagram of how these access rights will be implemented is shown in Fig. 7. This figure shows that for maximum flexibility a right can not only be applied to an individual BIM artefact, but also to all BIM artefacts in a BIM and all BIM artefacts within a stage of the project. Additionally, the functionality to allow role aggregation is present, allowing roles to be combined.

Another issue that must be considered is the formalizing of operations that can be performed on a BIM artefact. This includes the following: View BIM artefact, Create BIM artefact, Delete BIM artefact, Change BIM artefact suitability, Change access rights of BIM artefact.

\subsection{Change notification and version propagation}

In addition to the access control aspects of the governance model that have been outlined previously, other functionality has been developed based on consultation with industry. This functionality is based on two key requirements that have been gathered from our consultations:

- It is not acceptable for a user in another discipline to directly change a BIM artefact; i.e., a structural engineer should not be able to alter an architect's model. However, they may need to be able to request changes in the other BIM artefact to allow their own work to proceed;

- A user working in a related discipline may be interested in monitoring changes to a BIM artefact; i.e., the structural engineer will want to know when the changes they requested are completed.
Using these requirements, the concepts of notification (based on previous work by Cooper et al. (2005)) and flagging have been incorporated into our governance model. Notification is the ability for a user to monitor a BIM artefact for changes (such as the creation of a new version) and then have details about the transaction that caused the changes communicated to them by a chosen method. The concept of flagging is the process of the user raising a message on a BIM artefact, addressed to either another user or an entire discipline. These concepts are particularly important for cases where users are in close collaboration. The model describing this functionality is shown in detail in Fig. 8.

A complete view of the model is now presented in Fig. 9 highlighting the three main modelling constructs discussed in this section.

\section{Governance model validation}

A proof of concept BIM storage under the control of our governance model outlined previously has been constructed using the CometCloud (Kim, Parshar 2011) autonomic Cloud Computing framework. Utilisation of this framework allows us to leverage on the Master/Worker programming model supported by CometCloud, which utilises all computers within the cloud as either masters or workers. Fig. 10 shows how our prototype will scale to cover a multi-actor project, with several different companies involved. Within this figure, each company provides a set of workstations, each of which connects to a master. To a user it appears as if this master provides the data for the entire BIM, whereas in reality the data will be distributed amongst the workers. The master nodes do not store data, but they are responsible for integrating with the workers in the cloud by way of queries. Also, Fig. 10 illustrates how the master and worker capability is integrated into existing software, such as Autodesk Revit (used widely in the B\&C 


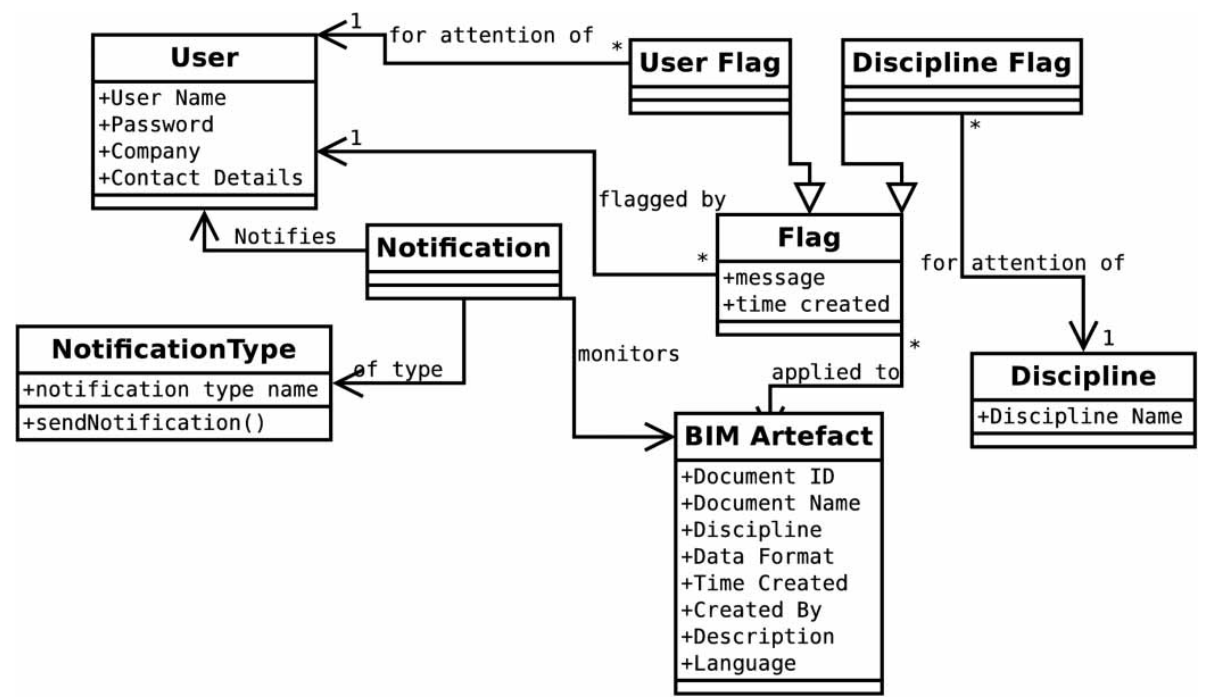

Fig. 8. Change notification and version propagation

domain) and Google Sketch-up (used for validation purposes in this section). The master node also acts as a security gateway enabling access to resources within the cloud based on the concepts described in section 5 . Each gateway contains a policy, developed as rules, which indicate which user (based on their discipline, associated rights and roles) can access which BIM artefact(s). In order to provide an initial validation of our governance model and cloud storage implementation, a case study is considered, using a University campus building, implemented in a laboratory environment. This case study involves three project industry partners, and interface to the governance model is achieved utilising a prototype client constructed using the Java programming language. The implemented use cases are provided by our partner project management company.

The use cases presented here illustrate how the governance model and prototype presented in this paper can be applied to a construction project. It can be assumed that such a project in the UK will be following the RIBA project stages and these stages will

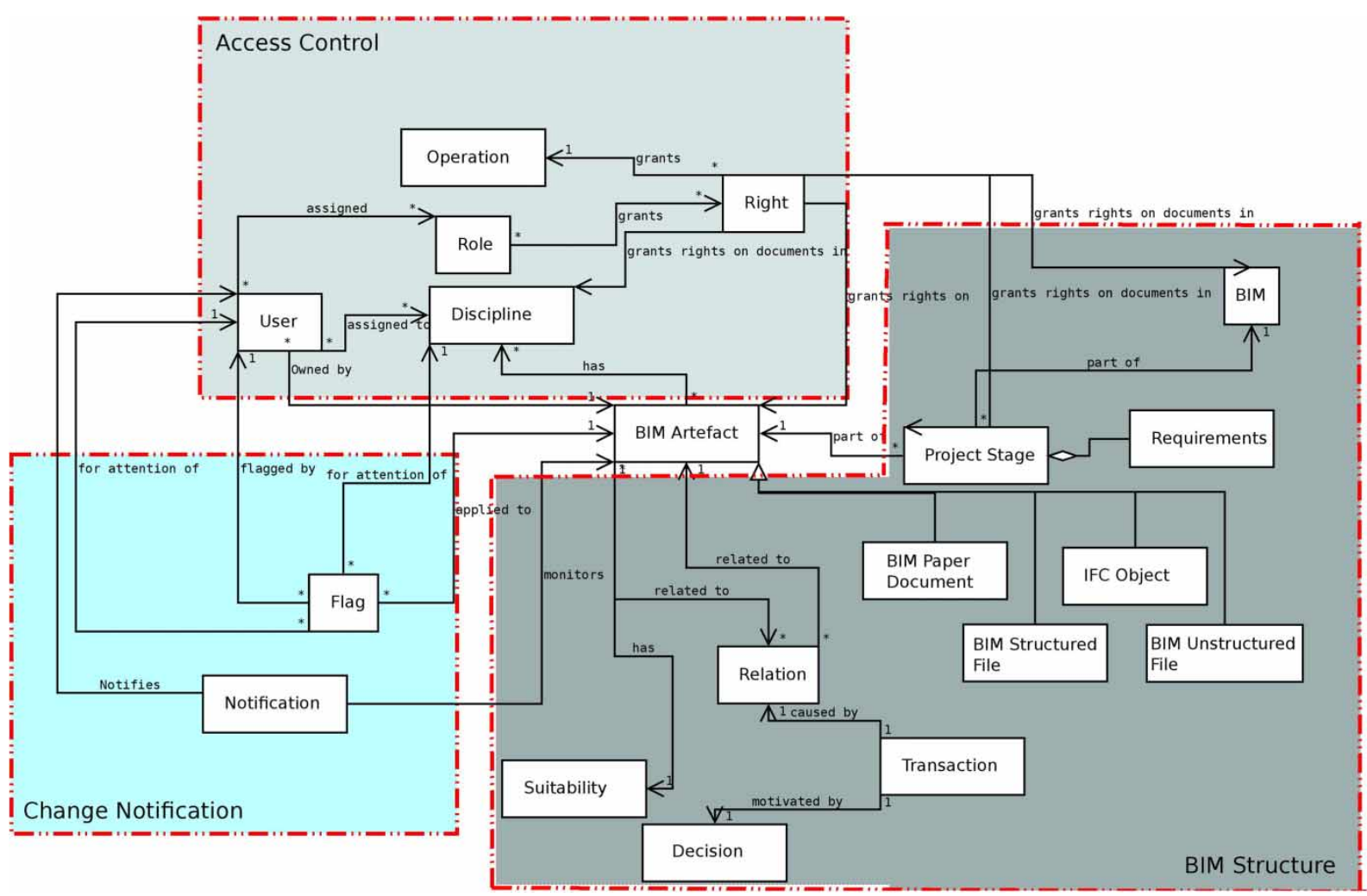

Fig. 9. Overall view of the governance model 


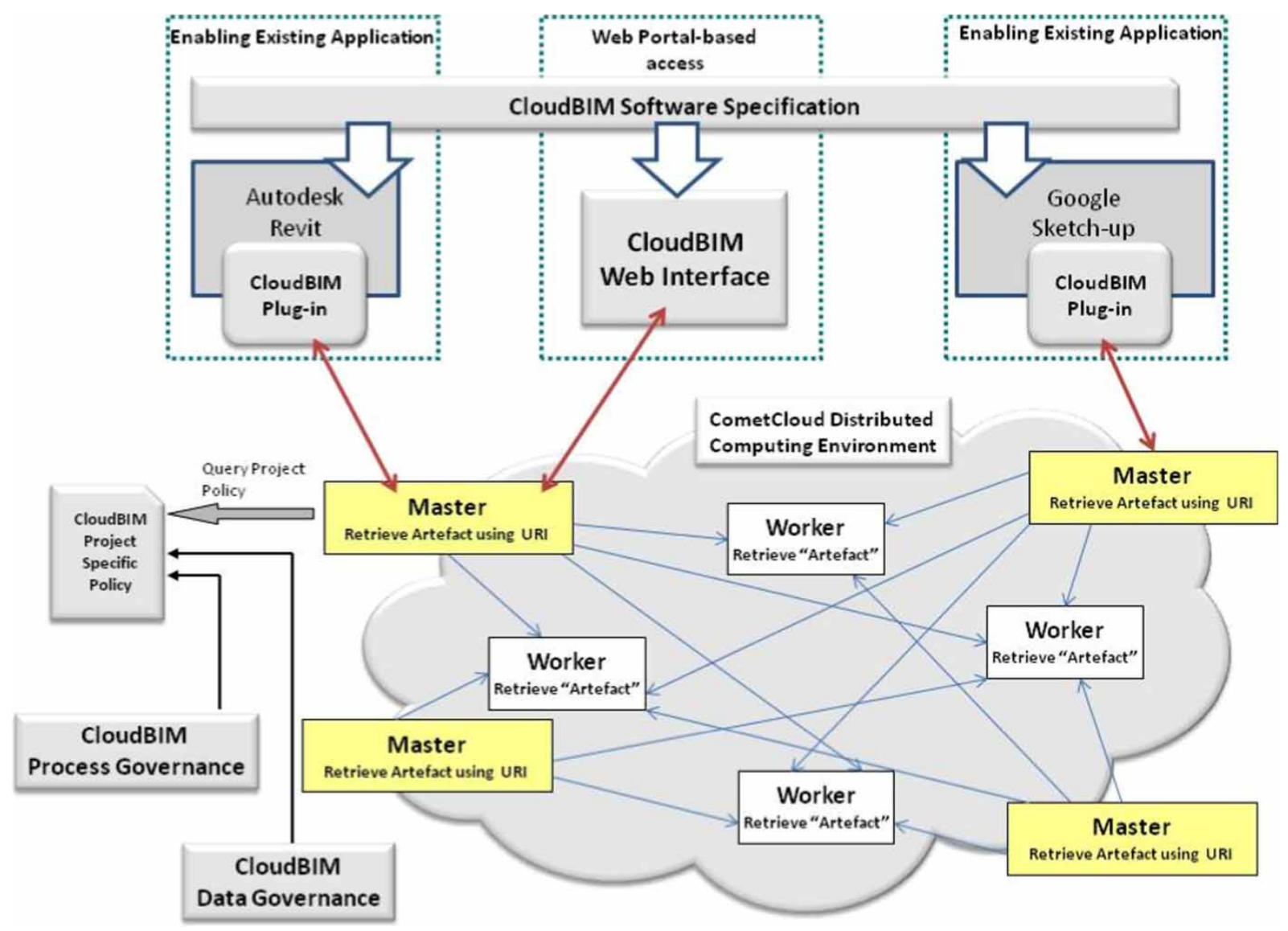

Fig. 10. CloudBIM system architecture

make up the project life-cycle as described in Section 5.3. Participating in the project there will be a small number of actors each assigned to a discipline as shown in Table 2.

To these users and disciplines, "roles" will be assigned granting each entity a set of rights on the "BIM artefacts" (as described in Section 5.5) within the governance model, listed in Table 3. The selection of one of these BIM artefacts allows the user to directly visualise its contents, whether they are a single file or a multi object BIM artefact.

A summary of these access rights is shown in Tables 3 and 4, involving the rights that apply to these BIM artefacts (i.e. Update, Read and Delete). Access rights in the demonstrator are granted at a "BIM Structured File" level; however, these also apply on a "BIM object" level, assuming that all objects within a given model inherit the same rights. Hence, the BIM

Table 2. Project disciplines and actors

\begin{tabular}{ll}
\hline User & \multicolumn{1}{c}{ Discipline } \\
\hline Architect & Architecture \\
Project Manager & Project Management \\
Structural Engineer & Structure \\
Mechanical Engineer & Mechanical \\
Electrical Engineer & Electrical \\
\hline
\end{tabular}

structured files involved in our cased study involve objects at different levels of granularity with attached stage-based access policies.

The early phases of design work on the project will be conducted by the Architecture discipline. A series of BIM artefacts, each detailing different design concepts, will be created by the architect. When an initial version of the design has reached a satisfactory completeness, the architect will review it and set its suitability to allow the other disciplines to utilise it. Fig. 11 shows how the prototype can model the versioning relationships between the versions of the architectural model and the metadata that is stored about each version of the BIM artefact. It also shows how the process of the BIM project is illustrated, with the RIBA project stages presented as tabs; these tabs are then highlighted green to signify which stages of the project have been completed. Currently architectural documents are added to and removed from our CloudBIM system by the use of an IFC compliant plug-in (IFC2SKP) developed for Google Sketchup, which is shown in Fig. 11.

These BIM structured files are linked through an optioning/versioning relationship whereby new versions of a "Revit" Architectural Model are produced in line with the progress of the design. It is worth noting that an IFC-based Curtain Wall specification is 
Table 3. Project BIM artefacts

\begin{tabular}{llll}
\hline BIM artefact & \multicolumn{1}{c}{ Discipline } & Suitability & Notes \\
\hline Architectural Model & Architecture & Finalized & $\begin{array}{l}\text { "Revit Architecture", IFC-based, models with several Versions } \\
\text { used to get to final model }\end{array}$ \\
$\begin{array}{l}\text { "Curtain Wall - CW324" } \\
\text { IFC object }\end{array}$ & Architecture & Finalized & $\begin{array}{l}\text { IFC-based specification of a Curtain Wall component from } \\
\text { manufacturer }\end{array}$ \\
$\begin{array}{l}\text { Structural Model } \\
\text { Building Energy Simulation } \\
\text { Electrical design } \\
\text { Activity Planning Document }\end{array}$ & $\begin{array}{l}\text { Structure } \\
\text { Mechanical } \\
\text { Electrical } \\
\text { Project } \\
\text { Management }\end{array}$ & $\begin{array}{l}\text { Team } \\
\text { Private } \\
\text { Private } \\
\text { Private }\end{array}$ & $\begin{array}{l}\text { "Ecotect" file derived from "Revit MEP" file derived from "Revit Architecture" document } \\
\text { "Microsoft Project" file }\end{array}$ \\
\hline
\end{tabular}

Table 4. Project access rights (update/read/delete)

\begin{tabular}{lccccc}
\hline BIM artefact & Architecture & Structure & Mechanical & Electrical & Project Management \\
\hline Architectural Model & $\mathrm{U} / \mathrm{R} / \mathrm{D}$ & $\mathrm{R}$ & $\mathrm{R}$ & $\mathrm{R}$ & $\mathrm{R}$ \\
"Window" IFC object & $\mathrm{U} / \mathrm{R} / \mathrm{D}$ & $\mathrm{R}$ & $\mathrm{R}$ & $\mathrm{R}$ & $\mathrm{R}$ \\
Structural Model & $\mathrm{R}$ & $\mathrm{U} / \mathrm{R} / \mathrm{D}$ & $\mathrm{R}$ & $\mathrm{R}$ & $\mathrm{R}$ \\
Building Energy Simulation & $\mathrm{R}$ & $\mathrm{R}$ & $\mathrm{U} / \mathrm{R} / \mathrm{D}$ & $\mathrm{R}$ & $\mathrm{R}$ \\
Electrical design & $\mathrm{R}$ & $\mathrm{R}$ & $\mathrm{R}$ & $\mathrm{U} / \mathrm{R} / \mathrm{D}$ & $\mathrm{R}$ \\
Activity Planning Document & $\mathrm{R}$ & $\mathrm{R}$ & $\mathrm{R}$ & $\mathrm{R}$ & $\mathrm{U} / \mathrm{R} / \mathrm{D}$ \\
\hline
\end{tabular}

included in the design (CW324-V1) which involves a composition relationship allowing the Curtain Wall object specification to evolve in parallel with the design.

Once the suitability of the architect's model has been changed the structural engineer can then view and create his model via a derivation relationship, which involves importing the architectural model into a structural package, in our case "Revit Structure". This is shown in Fig. 12 and it should be noted that the structural engineer can see BIM artefacts from their own discipline space, including the latest released

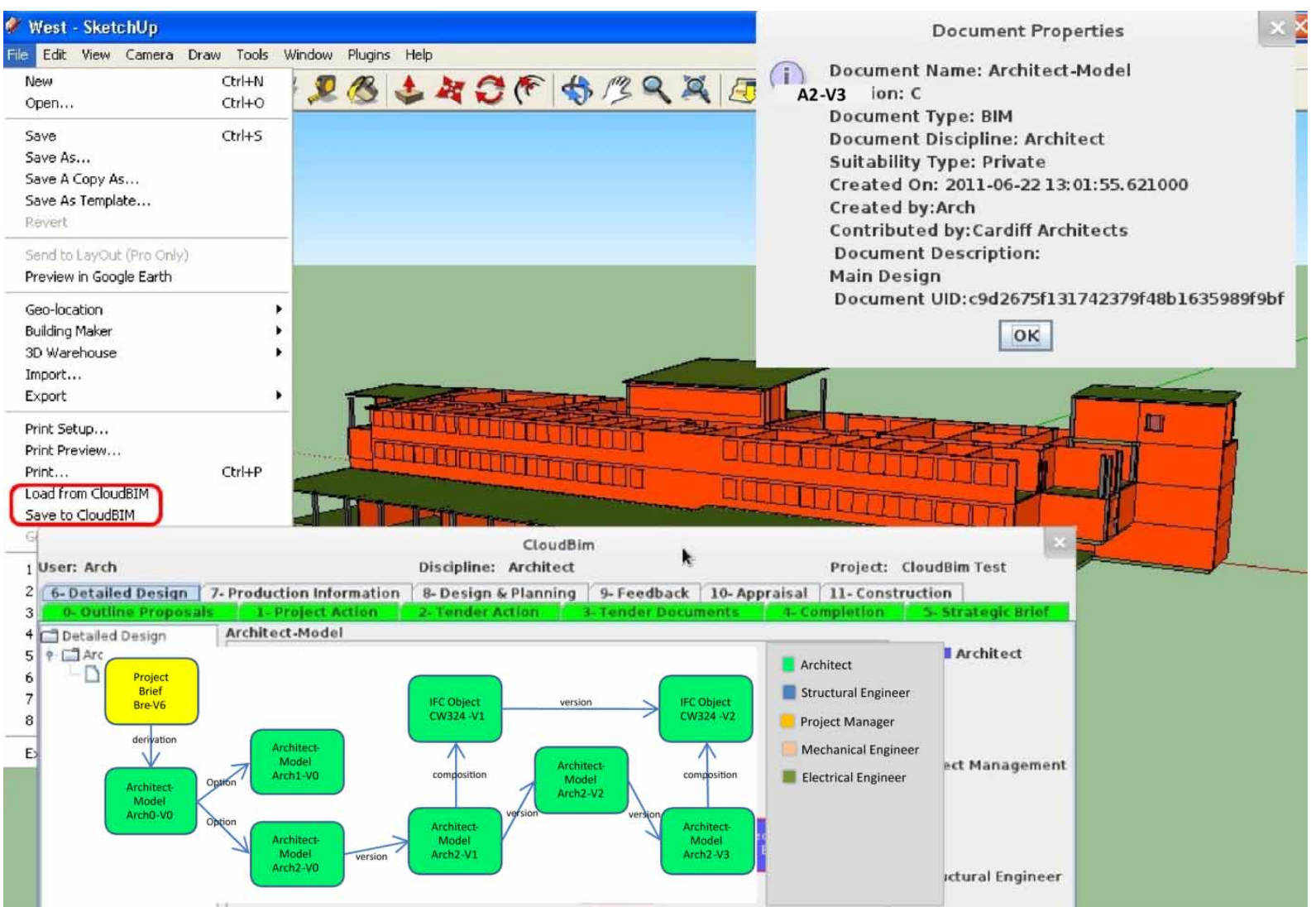

Fig. 11. CloudBIM prototype demonstrator with a focus on the architectural design 


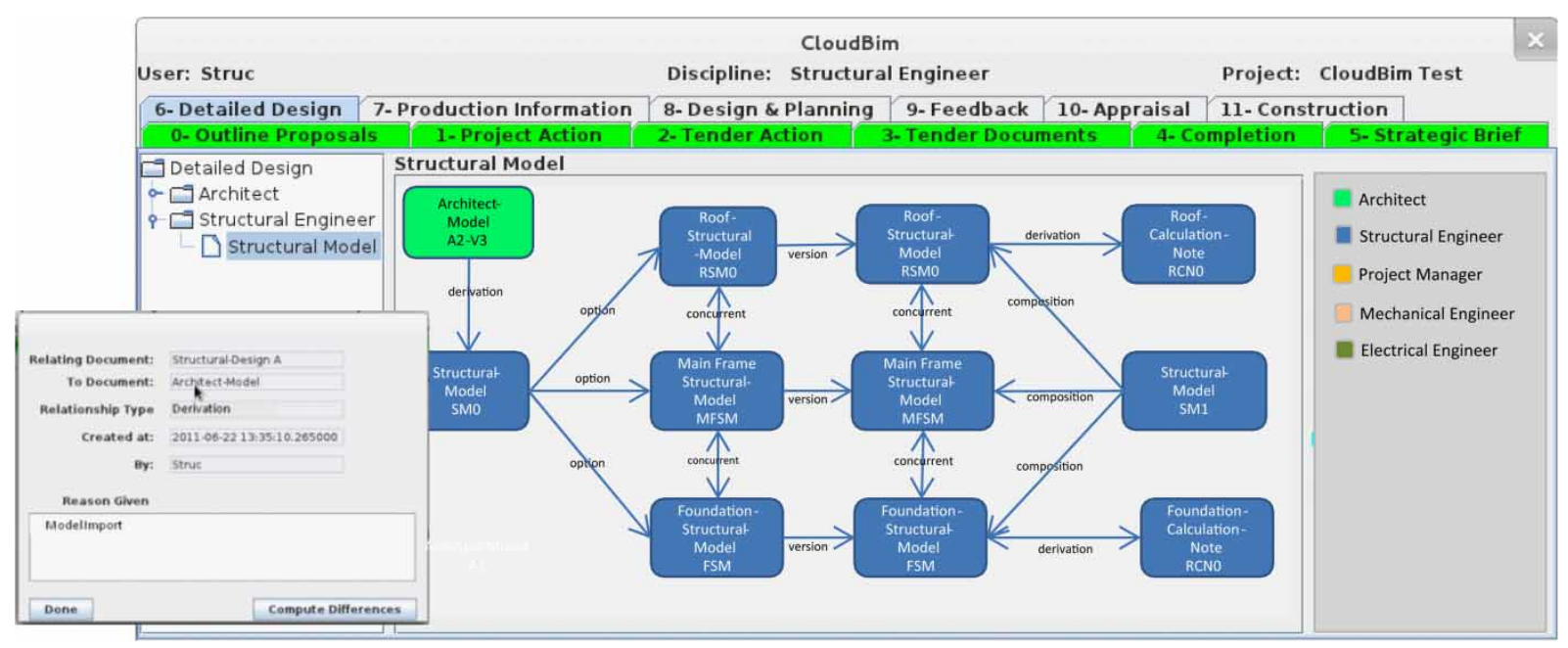

Fig. 12. Structural design progress management

version (A2-V3) of the architectural model (because its suitability type is set to finalised for the purpose of a particular RIBA stage). The derivation relationship and the metadata stored regarding the relationship between the architectural model and the structural analysis model is shown in Fig. 12. The structural model is organized into three sub-models (i.e. foundation, mainframe, and roof) which evolve separately (via a versioning relationship) before being merged back through a composition relationship into one model (model SM1).

As the design progresses, the project manager can monitor work progress and revise the project planning accordingly, as illustrated in Fig. 13. The project manager can access all project BIM artefacts with a "finalized status", their associated meta-data and contents. Several releases of the project planning are issued (plan-v1, plan-v2, plan-v3) informed by progress in the architectural (plan-v2) and other disciplines, mechanical, structure, and electrical (plan-v3).
It is interesting to note that all of above project BIM artefacts are stored and managed on the cloud distributed storage computing environment based on the proposed governance model. In a real context, data and BIM artefacts managed by the chosen "Data Centre" will be replicated across various physical sites, hence ensuring all time availability of data and BIM artefacts, while guaranteeing security, confidentiality, and intellectual property protection of contents, and at the same time reducing considerably potential for errors (due to handling the wrong version of a BIM artefact or non-access to relevant data for decision making).

\section{Discussion}

A number of products have appeared in the market focusing on supporting BIM data management. These include both open source and proprietary, vendorspecific systems. Open source systems include the BIM

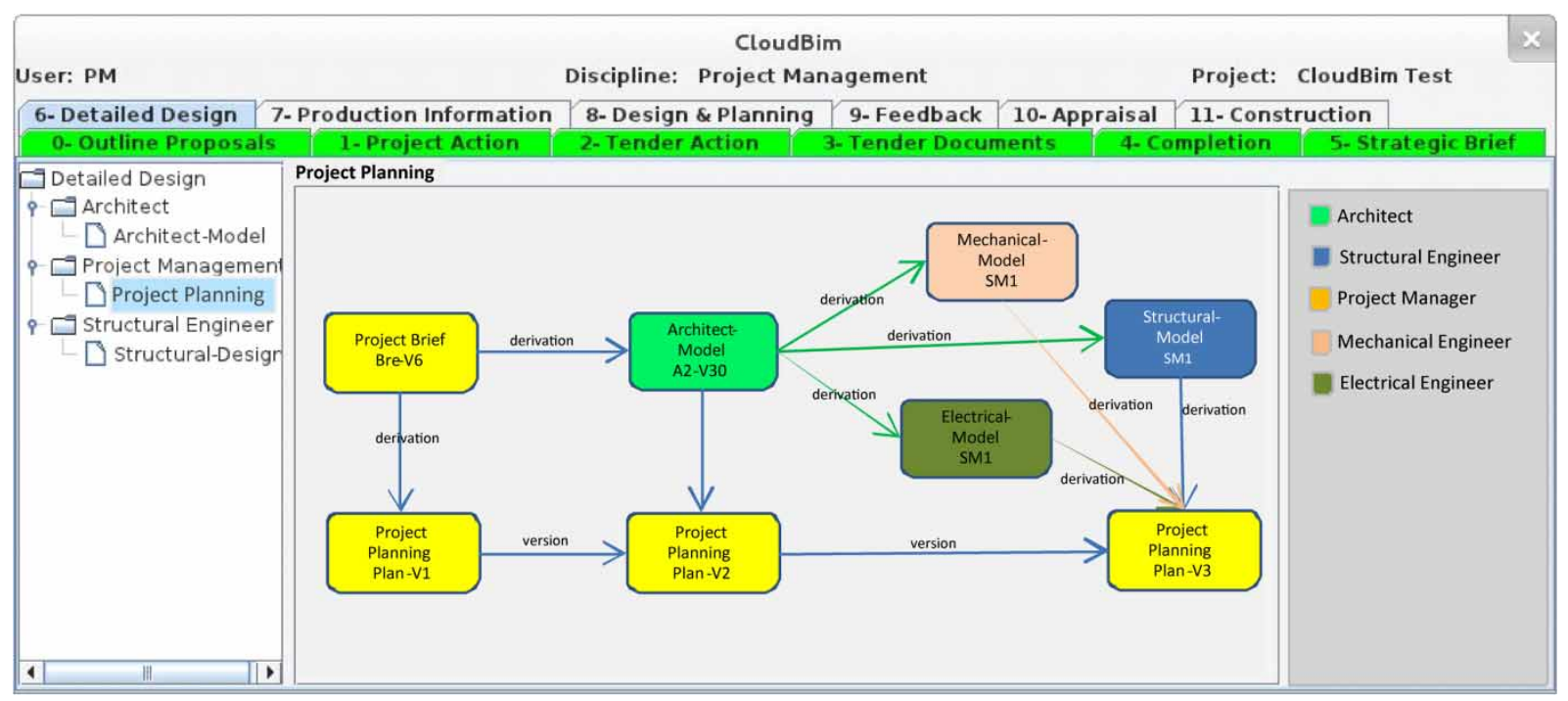

Fig. 13. Project management view 
Server (BIM Server 2012), Bentley Systems ProjectWise (ProjectWise 2012), OPS (OPS 2012), Horizontal Glue (Horizontal Glue 2012) and Ascite cBIM Manager (Ascite 2012). Most of these systems also support remote data hosting (similar to a Cloud environment), allowing a user to upload and store their data external to their own institution. One of the key drivers for this has been the need to support collaboration between different participants involved in a project.

The Ascite cBIM Manager enables interoperability across multi-vendor systems (such as Autodesk Revit and the Bentley architecture). This is achieved by supporting the Industry Foundation Classes (IFC), along with a 3D Viewer that enables rendering of the BIM model for visualisation. Similarly, the open source BIM Server (like Ascite cBIM Manager) also supports IFC and enables user specific schemas to be integrated using an XSLT (XML Schema Translation mechanism). Both systems also enable versioning of the BIM model, allowing the current version to be accessed from end user systems. Data sharing in both of these systems is comparable to OPS, which also supports IFC and enables integration with other data models such as KML (used in Google maps and Google Earth), along with specialist XML schemas (such as GBXML) and comma separated value (CSV) files. In particular the OPS Model Server supports multi-user collaboration for BIM data, supporting up to 3000 users as part of their BIMStorm system, and enabling different import/export capability to other formats (such as Autodesk Revit and Google Sketchup).

The Horizontal Glue system enables data integration using a "Glue Server", which enables multiple data models to be combined, providing detection of conflicts between these data models, and enabling user data to be time stamped on submission. This capability is useful to facilitate collaboration across a number of different users involved in the same project.

Our approach adopts a similar philosophy to the above systems, in that it also provides support for IFC - thereby ensuring that there is interoperability with a number of other commercial products. However, whereas other systems identified above only support data/document versioning, we also provide a number of other relationships between data to be supported such as optioning, concurrency, composition and derivation. In this way, we can for instance version a subset of a BIM data set and do not need to necessarily version the entire model. Based on industry consultation, we have found this additional level of granularity to be of much greater utility than capability supported in current systems. Additionally, our Cloud implementation enables support for both data storage and management (as in the systems identified above), but also support computational capability through the use of specialist "worker" processes. Each worker can be mapped to one or more virtual (or physical) machines, enabling simulation software to be integrated in the same way as data. Our access management capability also restricts access to particular BIM data depending on the user role and access requirements, and therefore enables a more coherent multi-party collaboration. This capability is also not supported in several systems identified above, most of which assume a single type of user accessing the system and do not differentiate between different user roles.

The paper has addressed the three research questions formulated earlier in the methodology section of the paper. Two deliberative industry workshops helped reach consensus around construction stakeholders' socio-organizational and technical barriers to BIM adoption in the UK (research question RQ1). These barriers have informed the development of a governance model that factors in the multidisciplinary, multi-actor, and lifecycle dimensions of construction projects. This governance model was developed in an incremental and iterative way, discussed in our second deliberative workshop and validated in our follow on focus group meetings. We are now in a position to provide a positive answer to our second research question (RQ2). The nature of the identified barriers (RQ1) and governance response (RQ2), informed by a comprehensive review of the technical literature, suggest that an outsourced BIM implementation based on our governance model provides a suitable environment to address data sharing and computing needs of construction stakeholders (research question RQ3). An implementation of our governance model using a distributed computing environment (i.e. Cloud model) is proposed which was discussed in our last two focus group meetings and tested in a laboratory environment with support from our industrial project partners. The focus group meetings outcomes confirmed the potential of the usefulness of using a distributed computing environment for outsourcing BIM to facilitate data sharing and governance.

This involves a paradigm shift as summarized in Fig. 14. However, this requires a staged implementation approach that takes into account the capability and maturity of construction companies, a majority of which are of a small or medium-sized nature.

One of the objectives of our EPSRC project (from which the research presented in the paper is funded) is to identify R\&D gaps and areas of research to increase BIM uptake in the UK and beyond. We have therefore developed a roadmap for BIM research and development fully informed by our consultation (including our proposed mixed-approach for information delivery). The proposed roadmap is structured around three main BIM adoption stages (BIM Stage 0, BIM Stage 1, and BIM Stage 2), emerged 


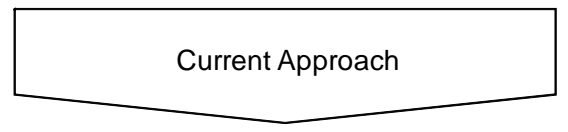

\begin{tabular}{|c|}
\hline $\begin{array}{c}\text { Ad-hoc means for managing distributed } \\
\text { and fragmented data }\end{array}$ \\
\hline $\begin{array}{c}\text { Hardware infrastructure is owned } \\
\text { / leased }\end{array}$ \\
\hline $\begin{array}{c}\text { Licensing is the prevailing model } \\
\text { for software provision }\end{array}$ \\
\hline $\begin{array}{c}\text { Collaboration between teams is at best } \\
\text { achieved via data file exchange }\end{array}$ \\
\hline $\begin{array}{c}\text { Data Intensive business processes } \\
\text { facilitated by software integration }\end{array}$ \\
\hline Desktop is the Computer \\
\hline
\end{tabular}

Fig. 14. Paradigm shift

from the consultation, involving socio-organizational and legal, process, and technology dimensions as illustrated in Fig. 15:

- BIM stage 0 assumes a document based approach to BIM. This corresponds to the lower level of our Fig. 15 whereby BIM involves a total lifecycle and multi-disciplinary set of contrac-

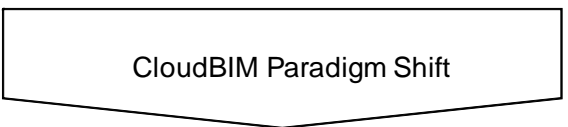

Governance Model that factors in

Trust, privacy, ownership and right issues

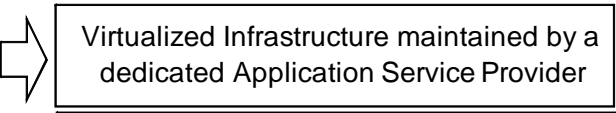

$\sqrt{\text { New business model based on "Software as }}$ a Service" and pay-per-use paradigm

$\sqrt{\quad \begin{array}{l}\text { Higher-order services centred around } \\ \text { Virtualized shared data repositories }\end{array}}$

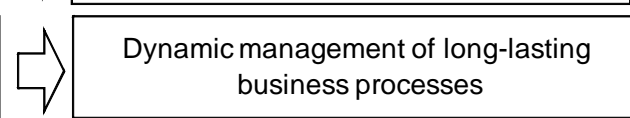

$\sqrt{\text { Full mobility: Network is the interface }}$

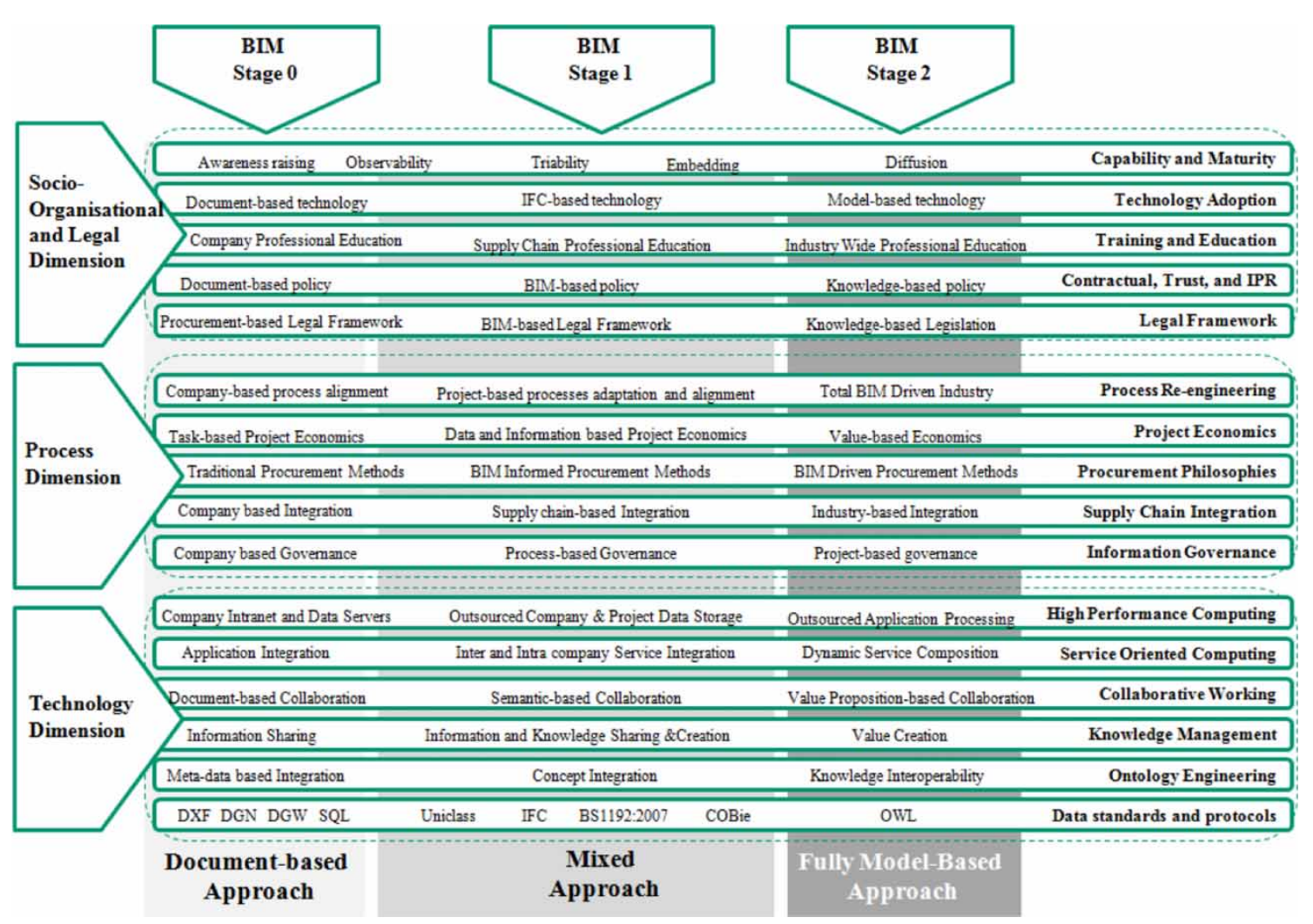

Fig. 15. BIM research and development roadmap 
- BIM stage 1 assumes a mixed approach illustrated by the co-existence of model-based (including IFC) and document-based information. A similar governance approach is used applied at different levels of granularity (i.e. document level and object level);

- BIM stage 2 assumes a fully model-based approach. This would require a more comprehensive development and release of the IFC that has the capability of describing multi-disciplinary project artefacts.

Each of the horizontal dimensions (socioorganizational and legal, process, and technology) involves a number of themes that have been inferred from the consultation results. This roadmap has been presented in a recent BIM workshop (1 November 2011) held at Cardiff University attended by $R \& D$ representatives of 25 companies from the construction sector in Wales and 10 academics from various universities in the UK. Overall feedback received was positive and the main recommendation was to pursue the roadmap in the context of strategic consultations with EPSRC (our UK research funding council that funded the research) with a view of informing their research funding strategy.

\section{Conclusion}

The paper presented a governance model for managing multi-actor, multi-discipline, and total lifecycle data, informed by a wide industry consultation in the UK. The study identifies a number of barriers and perceived reluctance in engaging with BIM efforts. Conversely, the consultation reveals increasing industry awareness about BIM spurred by recent government drives reflected in two recently published reports (BIM Working Party Strategy Paper 2011; HM Government 2011).

Construction project management includes: defining client's requirements; establishing good communication channels in which all parties can perform effectively; developing and managing change control procedures; and monitoring all decisions and approval in respect of the programme (RIBA 2007). The proposed governance model binds project stakeholders across disciplines and lifecycle around a shared BIM governance experience. An initial laboratory testing is described which suggests the need for a large scale validation of the model on a live project, in particular to validate some underpinning aspects of our governance model, including semantic of relationships between BIM artefacts. A roadmap for BIM adoption and diffusion is proposed that factors in the current structure of the industry and its various levels of stakeholders' maturity, capability and readiness.
Based on the literature review and conducted industry consultation, current evidence suggests that BIM can be used in current procurement methods. However, higher barriers will be experienced with some procurement paths due to hard separation between key project phases. Also, as noted earlier, there is a current gap in the contractual implications of BIM deployment on projects. Establishing these on a project level can be a complex and time consuming activity. These legal and contractual arrangements should be harmonized across industry. It is the belief of the authors as emerged from the consultation that the UK government can play a leading role in this facilitated by international organisations such as BuildingSMART, for instance through its BIM handbook (BuildingSMART 2010). Some aspects in relation to these legal and contractual issues can be found in national BIM guidelines, for instance in the NBIMS (NBIMS 2007) in the US, Senate Properties (Senate Properties 2007) in Finland, and CRC Construction Innovation (CRC 2009) in Australia and can be used for such additions.

It is hoped that the paper will inform companies about the challenges involved with the adoption and diffusion of BIM and at the same time provide a guide for future research in this area as illustrated in the proposed roadmap.

\section{Acknowledgements}

We would like to thank the anonymous reviewers for their recommendations that have enhanced the clarity and academic standing of our paper. The research was funded by the EPSRC in the UK in collaboration with Building Research Establishment (BRE), Bentley Systems, and Lee Wakemans.

\section{References}

Anumba, C. J.; Pan, R.; Issa, R. A; Mutis, I. 2008. Collaborative project information management in a semantic web environment, Engineering, Construction and Architectural Management 15(1): 78-94. http://dx.doi.org/10.1108/09699980810842089

Ascite. 2012. Ascite cBIM Manager [online]. [Cited 6 March 2012]. Available from Internet: http://www.asite. com/index.php/applications/category/application-cbimmanager/

Ashcraft, H. W. 2008. Building information modeling: a framework for collaboration, Construction Lawyer 28: $1-14$.

Barrett, P.; Sexton, M. 2006. Innovation in small, projectbased construction firms, British Journal of Management 17(4): 331-346. http://dx.doi.org/10.1111/j.1467-8551.2005.00461.x

BIM Server. 2012. [online]. [Cited 6 March 2012]. Available from Internet: http://code.google.com/p/bimserver/ wiki/Database_internals

BIM Working Party Strategy Paper. 2011. A report for the Government Construction Client Group, Commissioned 
by the Department of Business, Innovation and Skills. 34 p.

BuildingSMART. 2010. The BuildingSMART BIM Handbook.[online]. [Cited 6 March 2012]. Available from Internet: http://www.buildingsmart.com/

BS1192 2007 Collaborative production of architectural, engineering and construction information. Code of practice. British Standards Institution, 2008. 15 p.

Chao-Duivis, M. 2009. Legal implications of working with bim, Tijdschrift voor Bouwrecht 44: 204-212.

Cooper, G.; Cerulli, C.; Lawson, B. R.; Peng, C.; Rezgui, Y. 2005. Tracking decision-making during architectural design, Electronic Journal of Information Technology in Construction (ITCON) 10: 125-139.

CRC. 2009. National Guidelines for Digital Modelling. Techical Report. CRC for Construction Innovation. Icon. Net Pty Ltd. 54 p.

Dainty, A.; Moore, D.; Murray, M. 2006. Communication in construction: theory and practice. Abingdon, Oxon: Taylor \& Francis. 272 p.

East, E. W. 2010. Construction Operations Building Information Exchange (COBie) [online]. [cited 6 January 2012]. Available from Internet: http://www.wbdg.org/ resources/cobie.php

Eastman, C.; Teicholz, P.; Sacks, R.; Liston, K. 2011. BIM handbook: a guide to building information modelling for owners, managers, designers, engineers, and contractors. $2^{\text {nd }}$ ed. New Jersey: John Wiley and Sons, Inc. 648 p.

HM Government. 2011. Low carbon construction. Final Report. Innovation and growth team, UK. 35 p.

Horizontal Glue. 2012. [online]. [Cited 6 March 2012]. Available from Internet: http://www.horizontalsystems.com/index.php/products/glue-platform

Howard, R.; Björk, B.-C. 2008. Building information modelling: experts' views on standardisation and industry deployment, Advanced Engineering Informatics 22(2): 271-280. http://dx.doi.org/10.1016/j.aei.2007.03.001

ISO/PAS 16739:2005 Industry Foundation Classes, Release 2x, Platform Specification (IFC2x Platform). International Organization for Standardization, 2005. 205 p.

Kim, H.; Parashar, M. 2011. CometCloud: An autonomic cloud engine, in R. Buyya, J. Broberg, A. M. Goscinski (Eds.). Cloud Computing: Principles and Paradigms, Chapter 10, John Wiley, 275-297. http://dx.doi.org/10.1002/9780470940105.ch10

Koch, C.; Firmenich, B. 2011. An approach to distributed building modeling on the basis of versions and changes, Advanced Engineering Informatics 25(2): 297-310.

http://dx.doi.org/10.1016/j.aei.2010.12.001

Kubicki, S.; Halin, G.; Bignon, J. C.; Guerriero, A.; Hanser, D. 2006. A model-driven approach to design two assistance tools for building construction coordination, in ECPPM 2006 Conference - e-Business and e-Work in $A E C, 13-15$ September, 2006, Valencia, Spain. 8 p.

McGraw Hill. 2010. The business value of BIM in Europe: getting building information modeling to the bottom line in the United Kingdom, France and Germany. The McGraw Hill Companies. 242 p.

NBIMS. 2007. National Building Information Modeling Standard Part-1: Overview, Principles and
Methodologies. Techical Report. US National Institute of Building Sciences Facilities Information Council, BIM Committee. $182 \mathrm{p}$.

OPS. 2012. Onuma Planning System [online], [cited 6 March 2012]. Available from Internet: http://onuma.com/ products/BimDataApi.php and http://onuma.com/ products/OpsAndIfc.php

ProjectWise. 2012. ProjectWise [online], [cited 6 March 2012]. Available from Internet: http://www.bentley. com/en-US/Products/projectwise + project + team + collaboration/

Radziszewska-Zielina, E. 2010. Methods for selecting the best partner construction enterprise in terms of partnering relations, Journal of Civil Engineering and Management 16(4): 510-520.

http://dx.doi.org/10.3846/jcem.2010.57

Rana, O.; Beach, T.; Rezgui, Y.; Parashar, M. 2011. Governance model for cloud computing in building information management, in 10th e-Science All Hands Meeting (AHM) - Towards the Cloud: Infrastructures, Applications, Research, September, 2011, York, UK.

Rezgui, Y.; Zarli, A. 2006. Paving the way to the vision of digital construction: a strategic roadmap, Journal of Construction Engineering and Management ASCE 132(7): 767-776. http://dx.doi.org/10.1061/(ASCE) 0733-9364(2006)132:7(767)

Rezgui, Y.; Miles, J. 2011. Harvesting and managing knowledge in construction: from theoretical foundations to business applications. Spon Press, UK. 232 p.

Rezgui, Y.; Cooper, G.; Brandon, P. 1998. Information management in a collaborative multiactor environment: The COMMIT approach, Journal of Computing in Civil Engineering ASCE 12(3): 136-144. http://dx. doi.org/10.1061/(ASCE)0887-3801(1998)12:3(136)

RIBA. 2007. Outline Plan of Work 2007. Royal Institute British Architects, UK. 3 p.

Sebastian, R. 2010. Breaking through business and legal barriers of open collaborative processes based on Building Information Modelling (BIM), in Proc. of 18th CIB World Building Congress, May 2010, Salford, United Kingdom, 166-186.

Senate Properties. 2007. BIM Requirements. Technical Report. Senate Properties, UK. 12 p.

Serror, M. H.; Inoue, J.; Adachi, Y.; Fujino, Y. 2008. Shared computer-aided structural design model for construction industry (infrastructure), Computer-Aided Design 40(7): 778-788.

http://dx.doi.org/10.1016/j.cad.2007.07.003

Singh, V.; Gu, N.; Wang, W. 2011. A theoretical framework of a BIM-based multi-disciplinary collaboration platform, Automation in Construction 20(2): 134-144. http://dx.doi.org/10.1016/j.autcon.2010.09.011

Smith, A.; Stirling, A.; Berkhout, F. 2005. The governance of socio-technical transitions, Research Policy 34(10): $1491-1510$. http://dx.doi.org/10.1016/j.respol.2005.07.005

Smith, D. K.; Tardif, M. 2009. Building information modeling: a strategic implementation guide for architects, engineers, constructors, and real estate asset managers. Hoboken, NJ: Wiley. 216 p.

Succar, B. 2009. Building information modelling framework: a research and delivery foundation for industry 
stakeholders, Automation in Construction 18(3): $357-375$.

http://dx.doi.org/10.1016/j.autcon.2008.10.003

Titus, S.; Bröchner, J. 2005. Managing information flow in construction supply chains, Construction Innovation: Information, Process, Management 5(2): 71-82.

Ulubeyli, S.; Manisali, E.; Kazaz, A. 2010. Subcontractor selection practices in international construction pro- jects, Journal of Civil Engineering and Management 16(1): 47-56. http://dx.doi.org/10.3846/jcem.2010.04

Zavadskas, E. K.; Turskis, Z.; Tamošaitiene, J. 2010. Risk assessment of construction projects, Journal of Civil Engineering and Management 16(1): 33-46. http://dx.doi.org/10.3846/jcem.2010.03

Yacine REZGUI. Professor in Engineering Informatics and is the director of the BRE Institute in Sustainable Engineering at Cardiff University. He has a background in architecture (including several years of experience in design practice) and $\mathrm{PhD}$ in computer science. He conducts research in the application of ICT to the construction sector. He has successfully completed, seventeen UK (EPSRC) and EC (Framework 4, 5, 6 and eContent) funded projects. He has published extensively in areas related to knowledge engineering and collaborative working, and his papers appeared in leading journals such as Computer-Aided Design, Information Sciences, and Knowledge Engineering Review.

Thomas BEACH. Holds a PhD in Computer Science. He was the lead researcher on the CloudBIM project (described in this paper). He has expertise in governance aspects of electronic information and high performance computing.

Omer RANA. Professor in Performance Engineering at Cardiff University, and was formerly the deputy director of the Welsh eScience Centre. He holds a PhD in "Neural Computing and Parallel Architectures" from Imperial College, London University. He led a work package in the FP6 "SORMA" project, the aim of which was to develop an electronic market for exchanging Grid and Cloud computing resources. His recent work has involved developing "Social Clouds" - primarily by integrating social network sites (such as Facebook) with Cloud computing capability and charging models (based on "virtual credits" available in Facebook). He is a member of the steering committee of the IEEE/ACM conference on "Grid, Cloud and Cluster Computing". 